\title{
Supplementary material to the paper: Ten years of MIPAS measurements with ESA Level 2 processor V6 - Part I: retrieval algorithm and diagnostics of the products
}

\author{
P. Raspollini, B. Carli, M. Carlotti, S. Ceccherini, A. Dehn, B. M. Dinelli,
} A. Dudhia, J. M. Flaud, M. López-Puertas, F. Niro, J. J. Remedios, M. Ridolfi, H. Sembhi, L. Sgheri, T. von Clarmann

This document contains some figures that complete the information provided in the paper. In particular, Fig.4 of the paper, showing Ozone percent random and systematic error profiles for the reference atmospheres for both FR and OR measurements, and Figs 7 and 8 of the paper, showing the Ozone AKs for two representative scans from FR and OR measurements, are here repeated for the other species retrieved by the ESA processor ML2PP V6. 

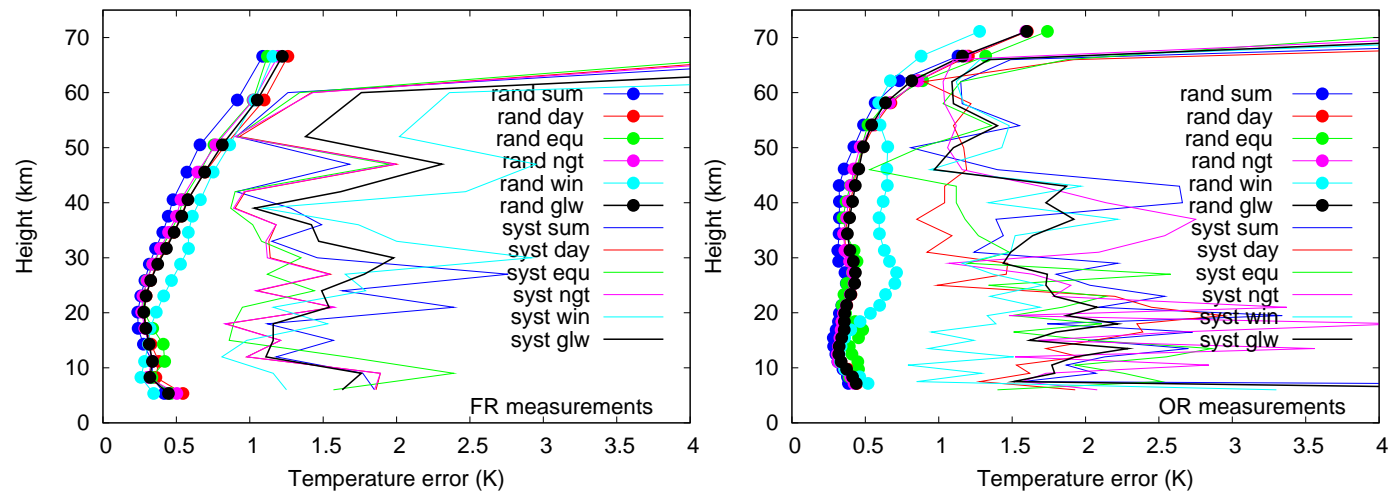

Figure 1: Percent random and systematic errors of temperature profile retrieved from FR (left plot) and OR (right plot) measurements. For the description of the reference atmospheres for which random and systematic errors are provided refer to Fig. 4 of the paper.
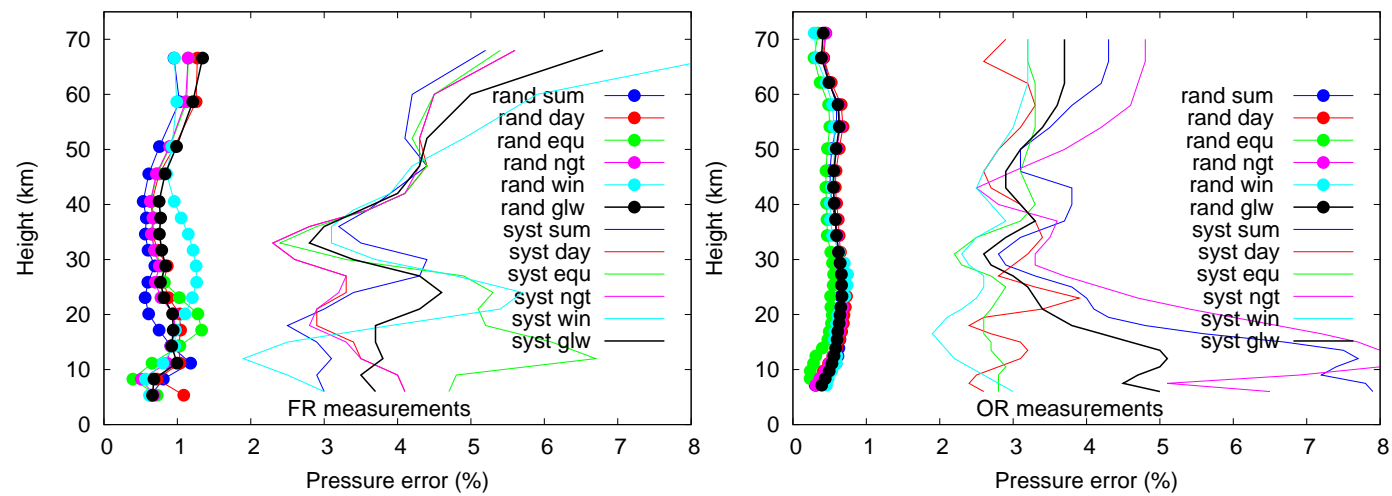

Figure 2: Same as Fig.1, but for pressure.
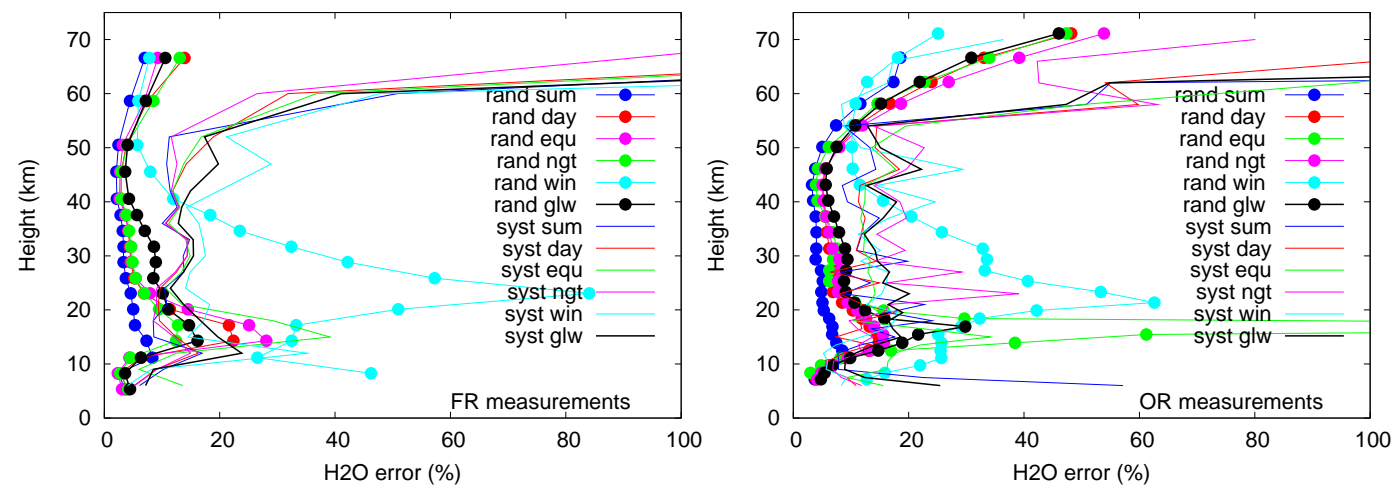

Figure 3: Same as Fig.1, but for $\mathrm{H}_{2} \mathrm{O}$. 

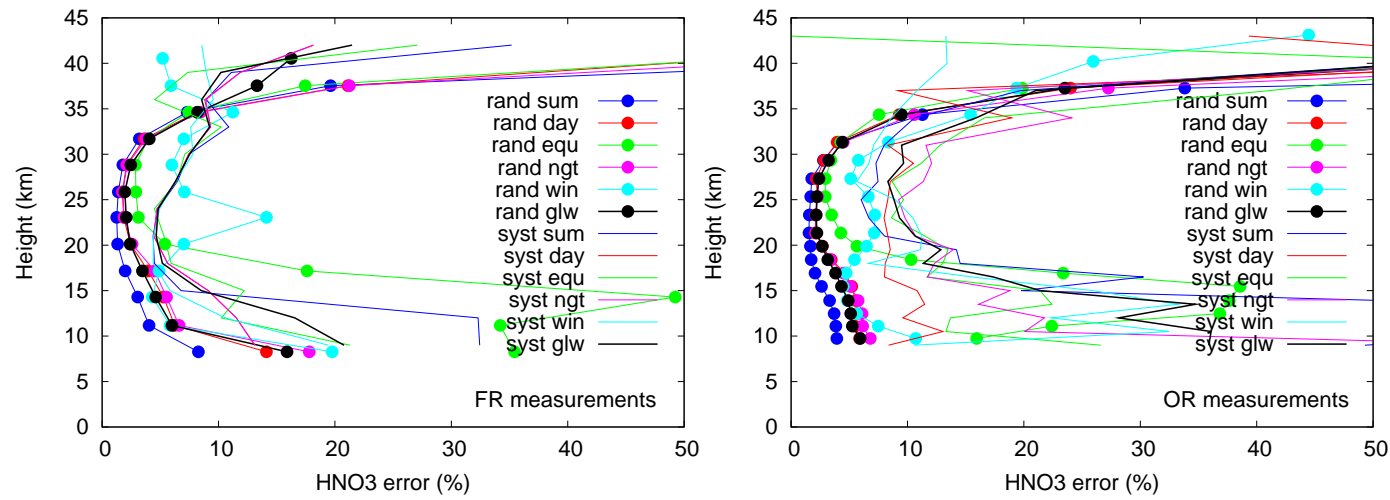

Figure 4: Same as Fig.1, but for $\mathrm{HNO}_{3} \mathrm{O}$.
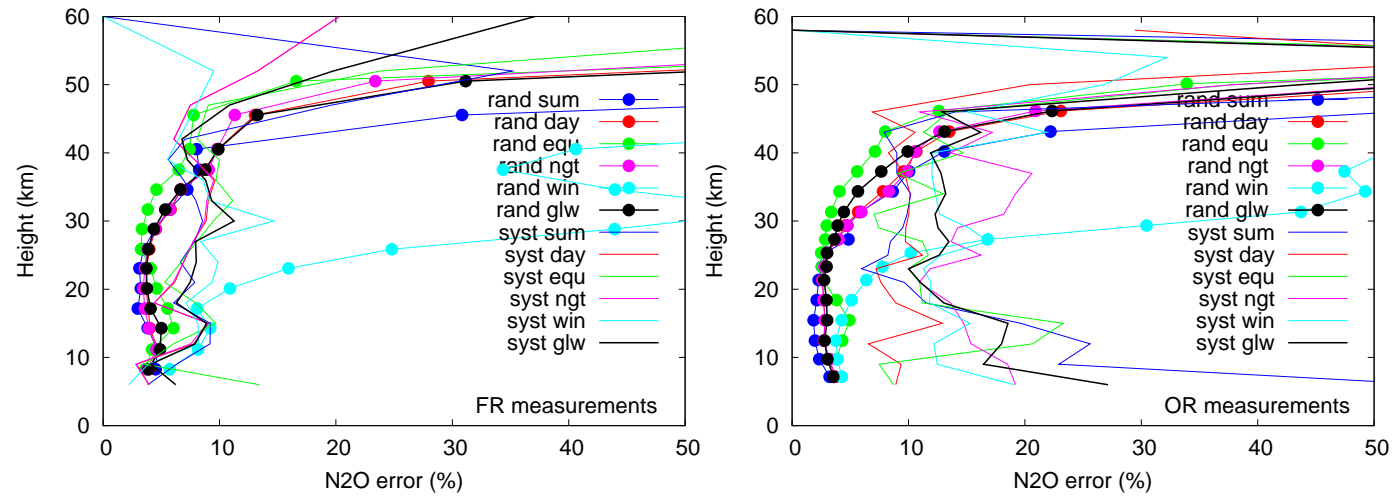

Figure 5: Same as Fig.1, but for $\mathrm{N}_{2} \mathrm{O}$.
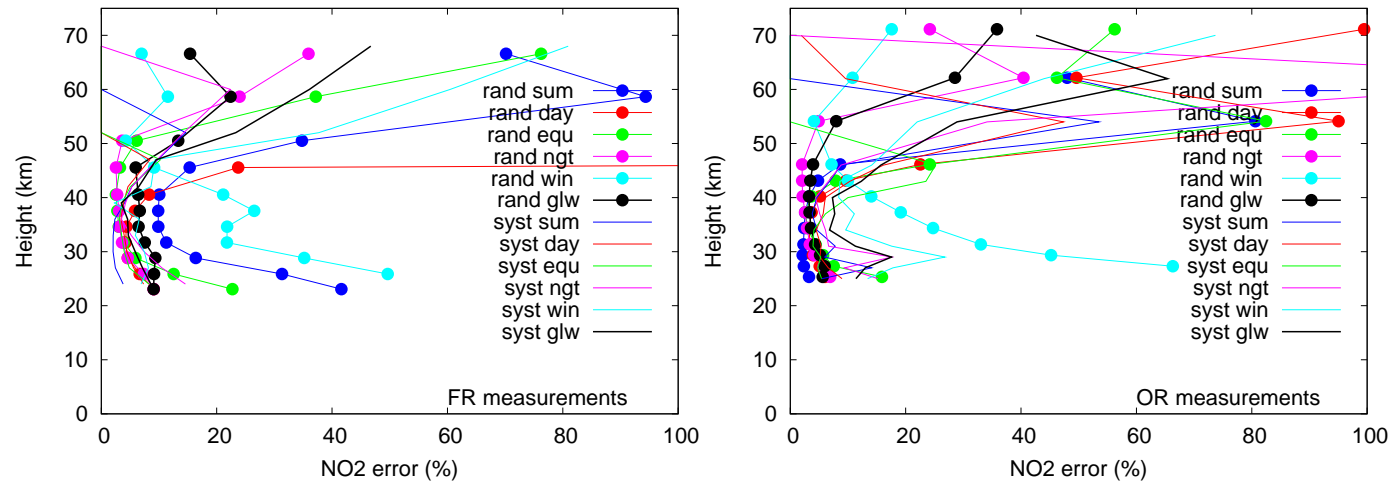

Figure 6: Same as Fig.1, but for $\mathrm{NO}_{2}$. 

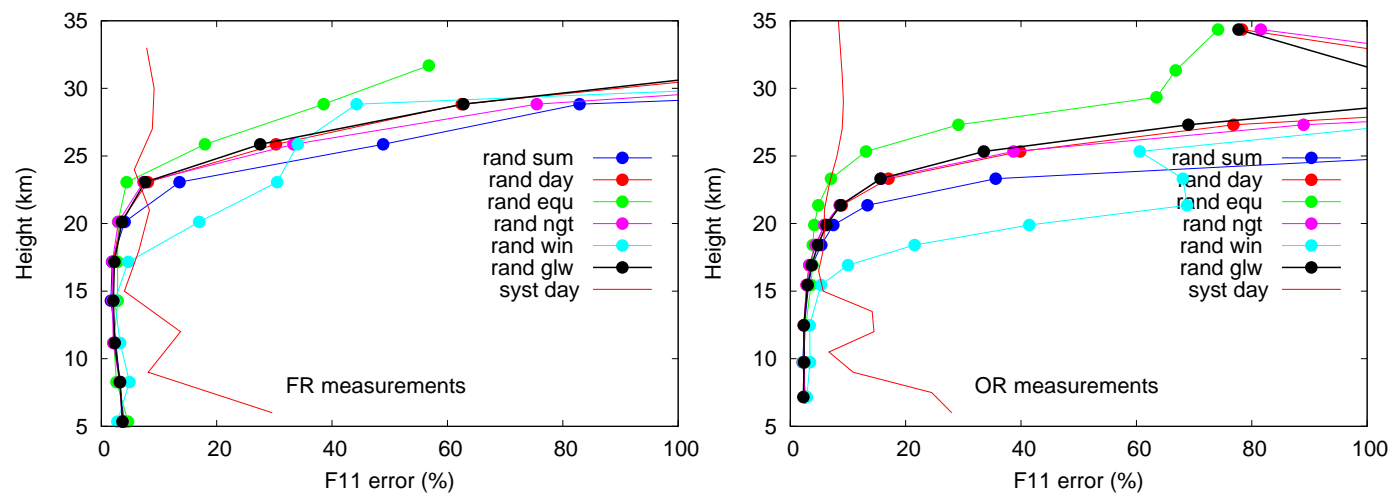

Figure 7: Same as Fig.1, but for CFC-11.
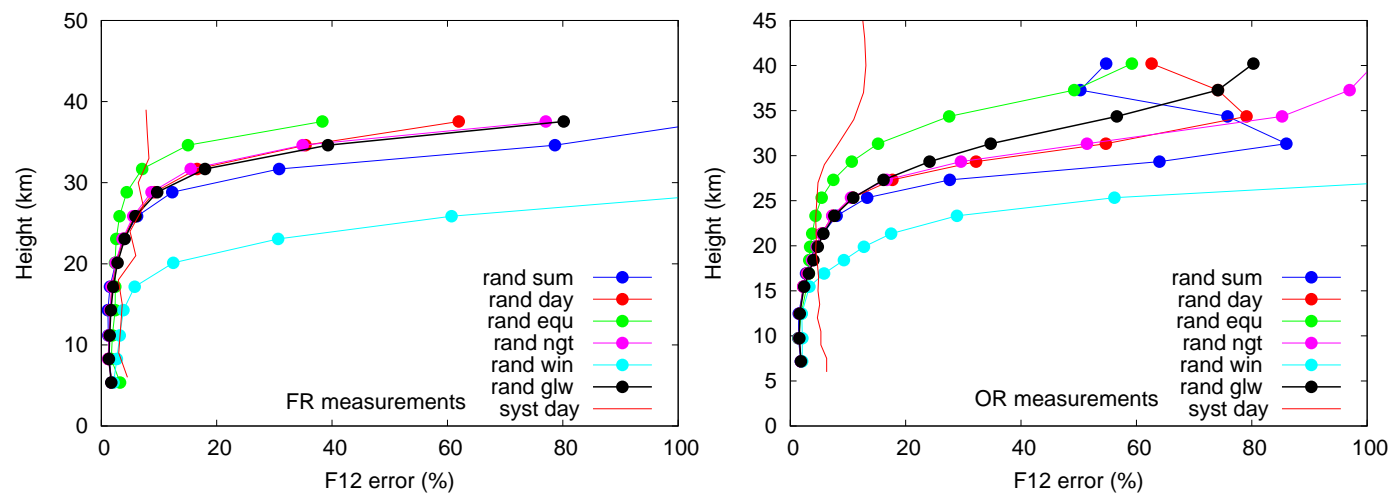

Figure 8: Same as Fig.1, but for CFC-12.
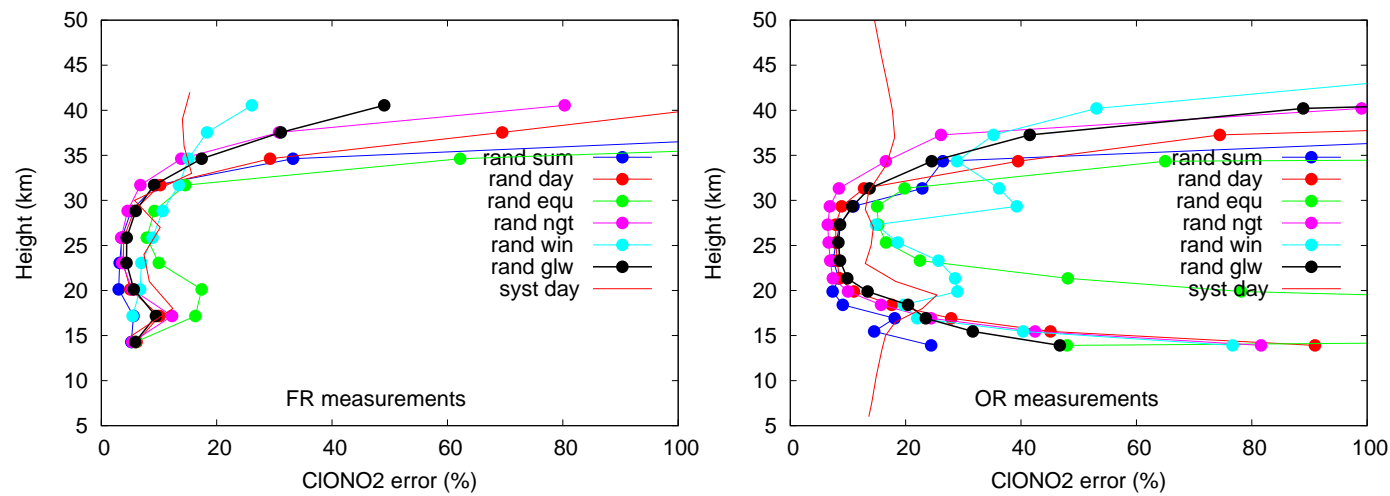

Figure 9: Same as Fig.1, but for $\mathrm{ClONO}_{2}$. 

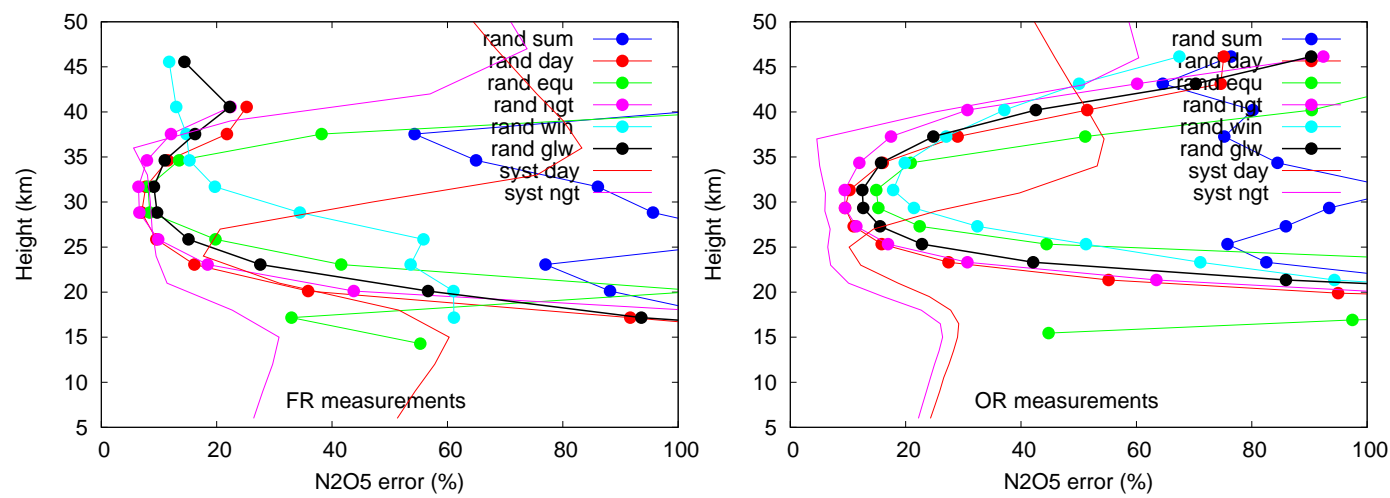

Figure 10: Same as Fig.1, but for $\mathrm{N}_{2} \mathrm{O}_{5}$. 

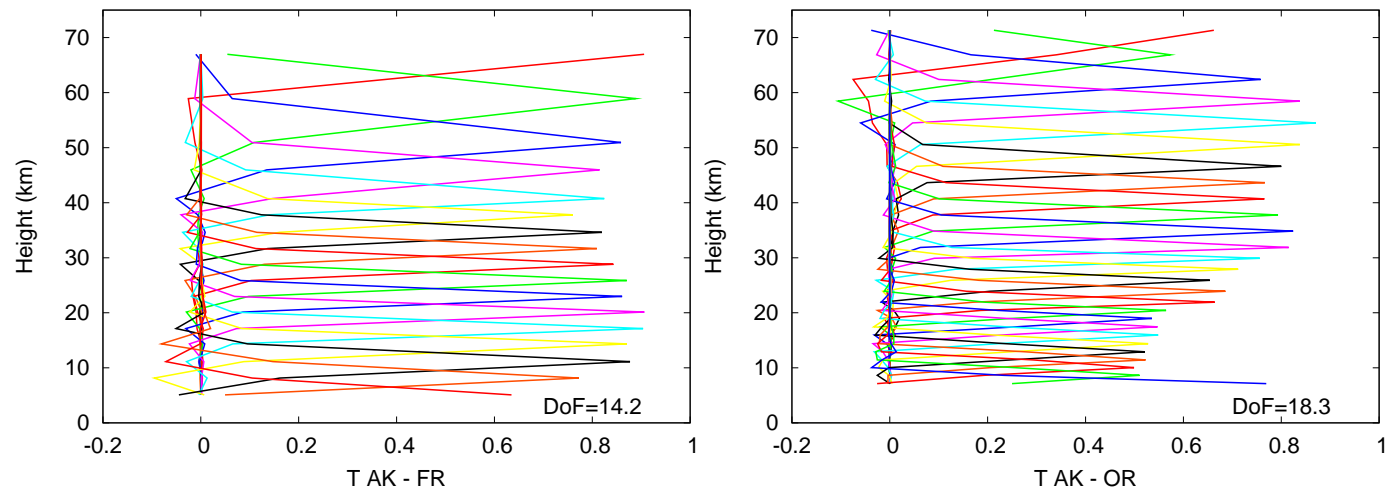

Figure 11: Temperature AKs for two representative scans of FR (left plot) and OR (right plot) measurements
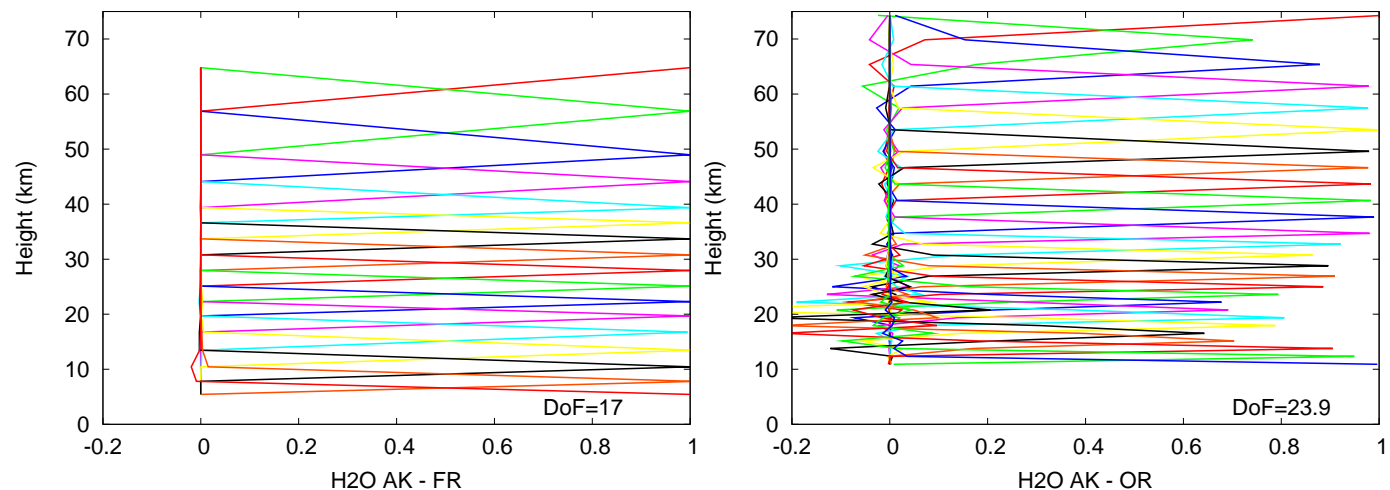

Figure 12: Same as Fig.11, but for $\mathrm{H}_{2} \mathrm{O}$.
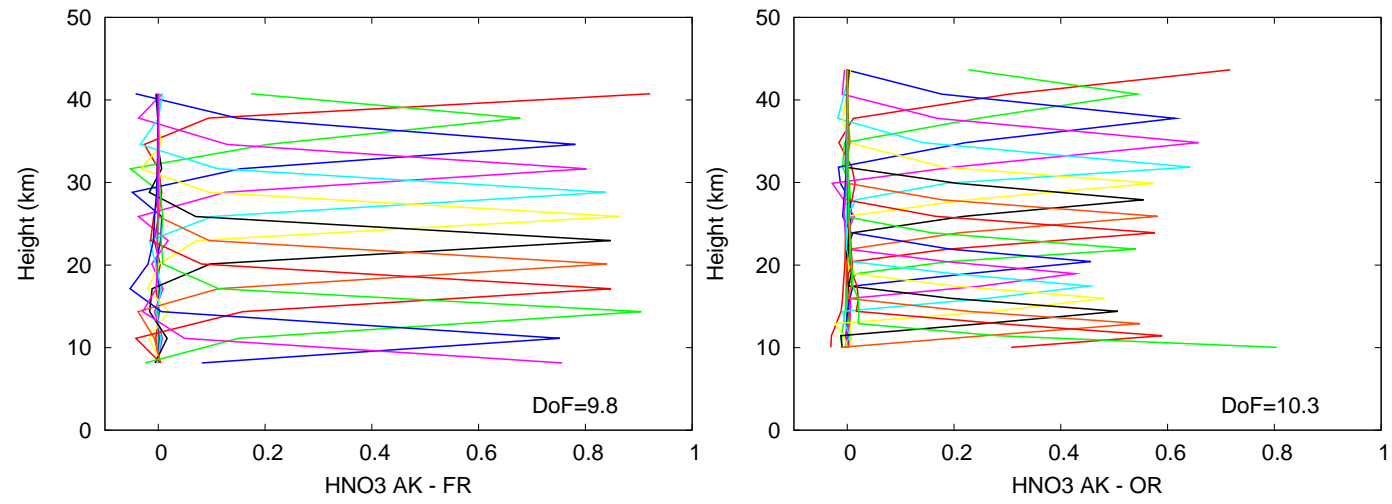

Figure 13: Same as Fig.11, but for $\mathrm{HNO}_{3}$. 

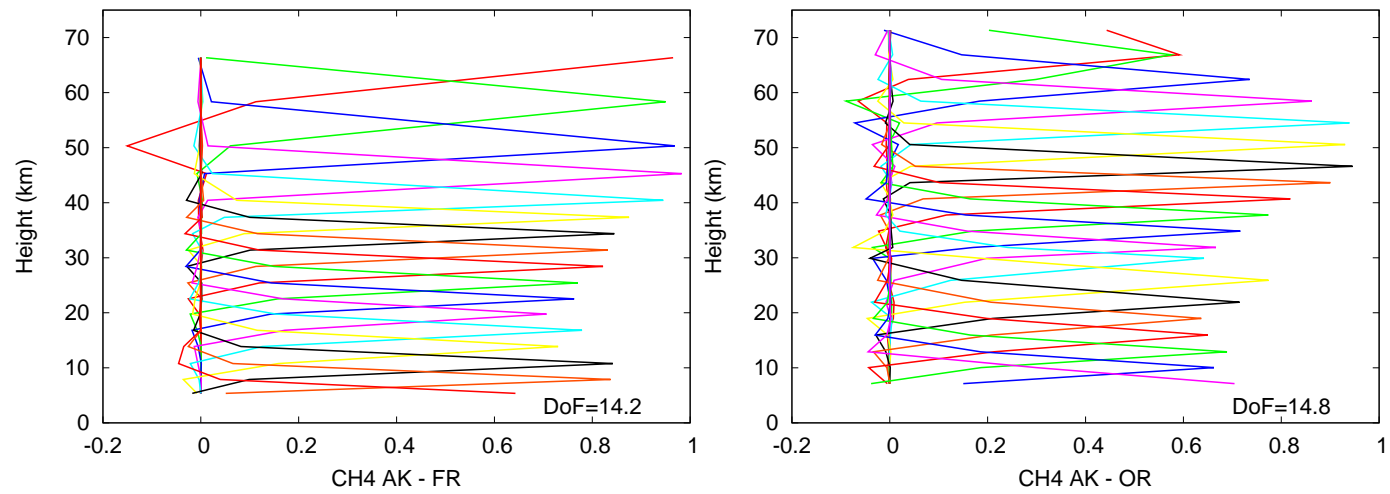

Figure 14: Same as Fig.11, but for $\mathrm{CH}_{4}$.
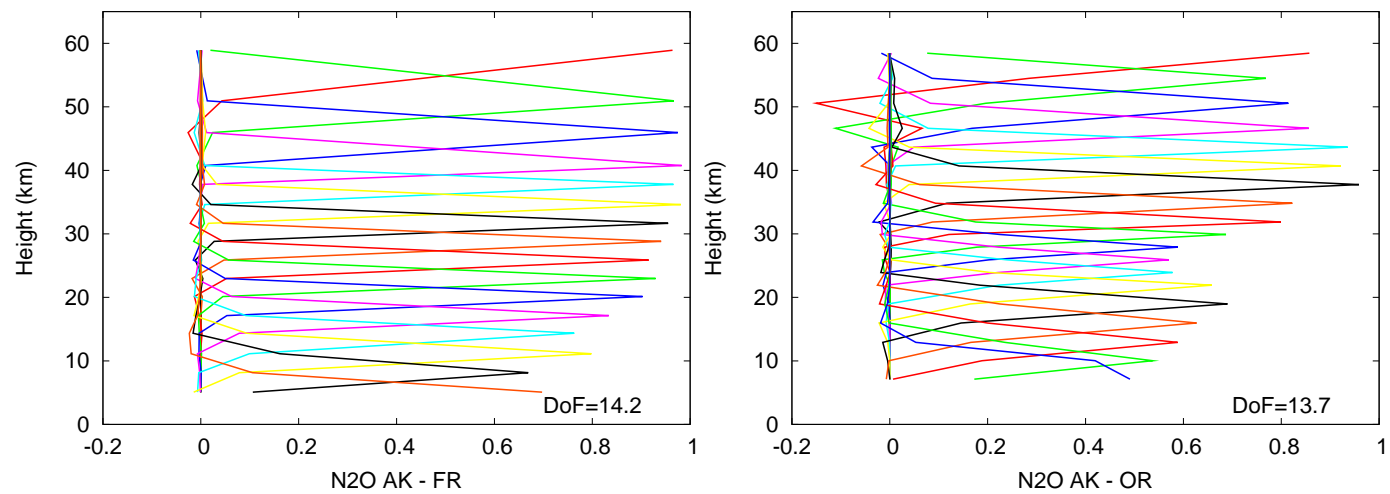

Figure 15: Same as Fig.11, but for $\mathrm{N}_{2} \mathrm{O}$.
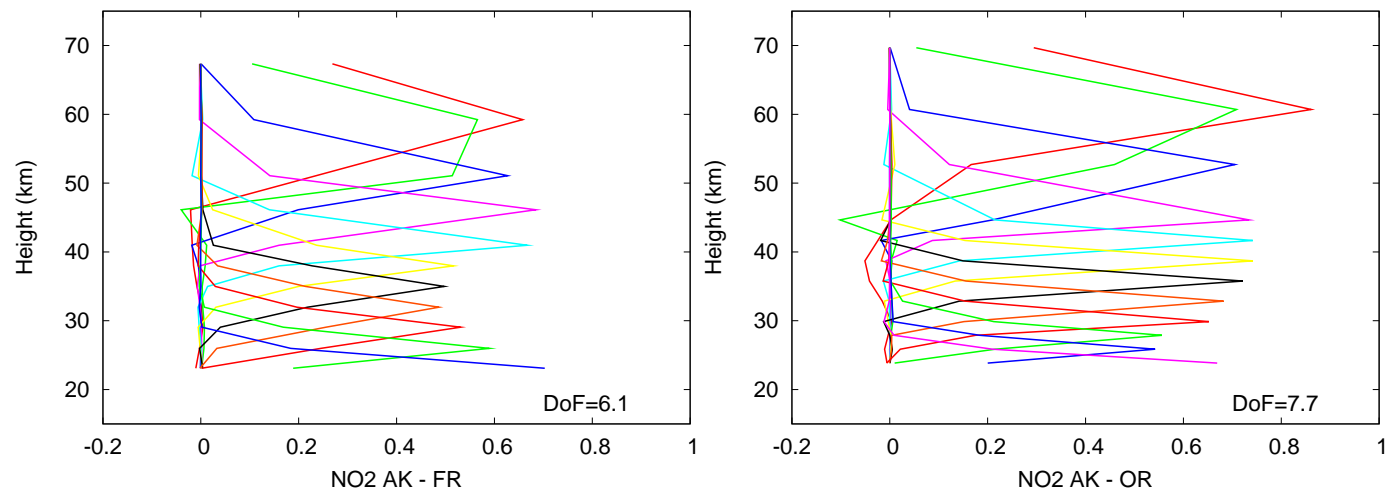

Figure 16: Same as Fig.11, but for $\mathrm{NO}_{2}$. 

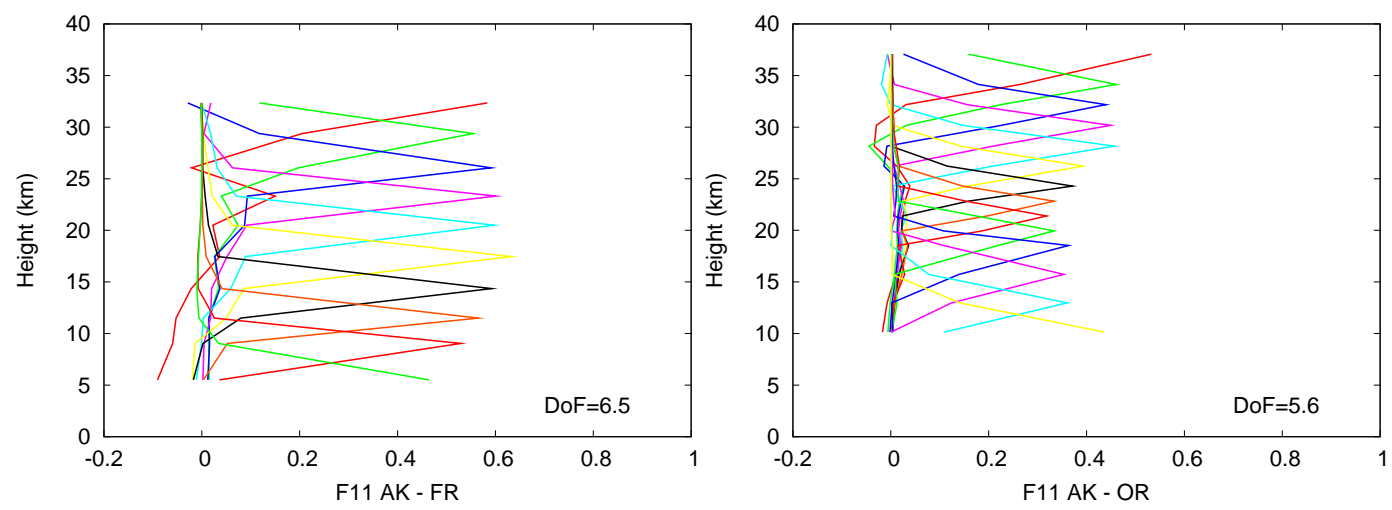

Figure 17: Same as Fig.11, but for CFC-11.
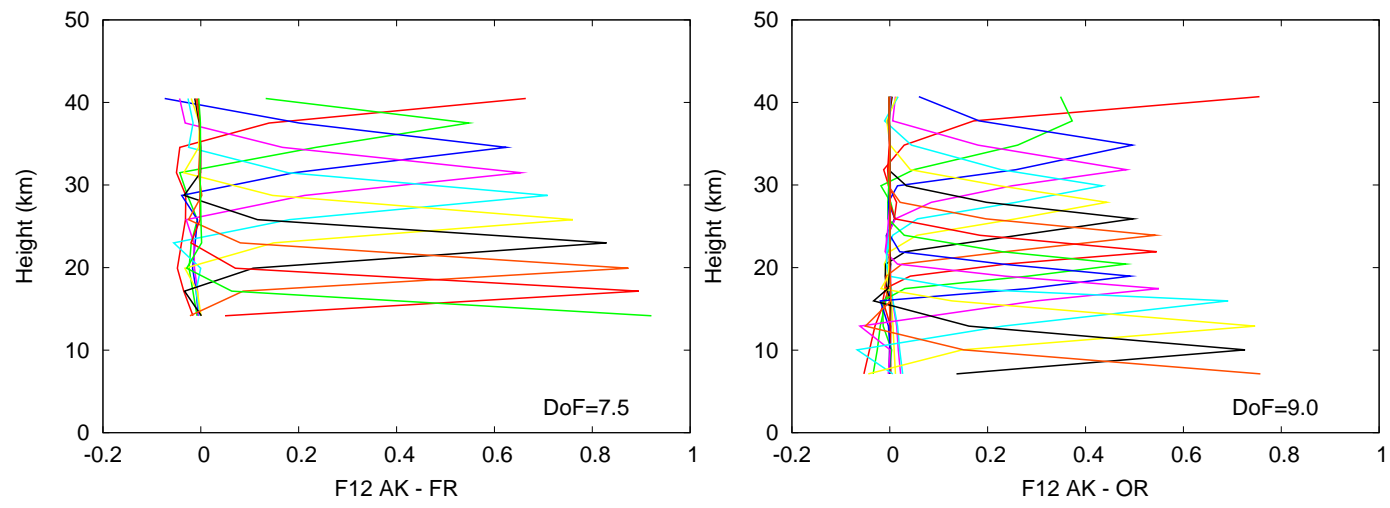

Figure 18: Same as Fig.11, but for CFC-12.
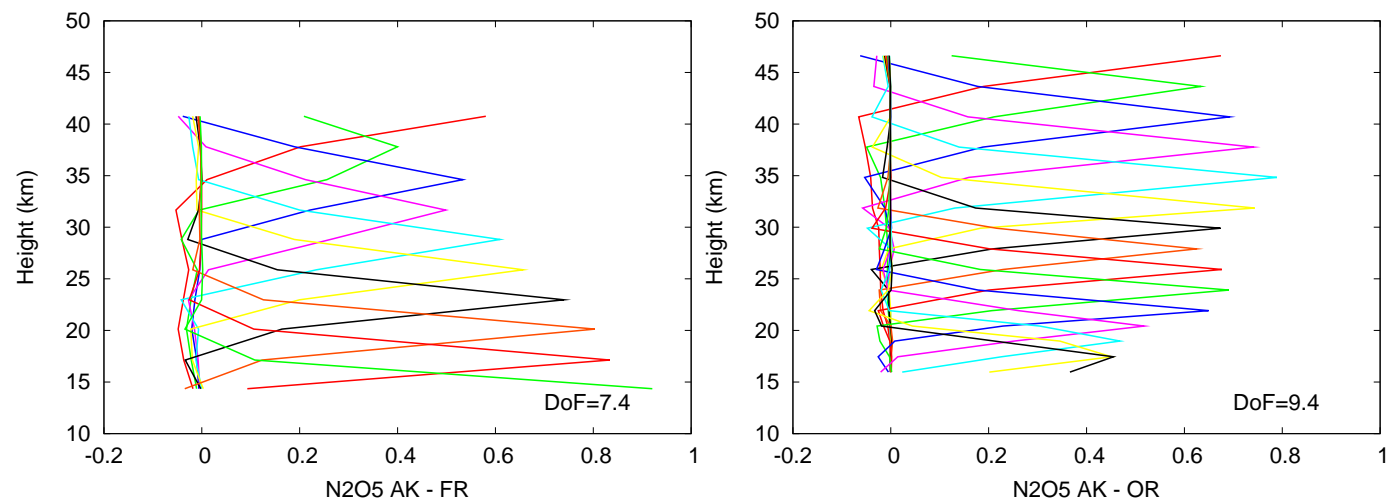

Figure 19: Same as Fig.11, but for $\mathrm{N}_{2} \mathrm{O}_{5}$. 

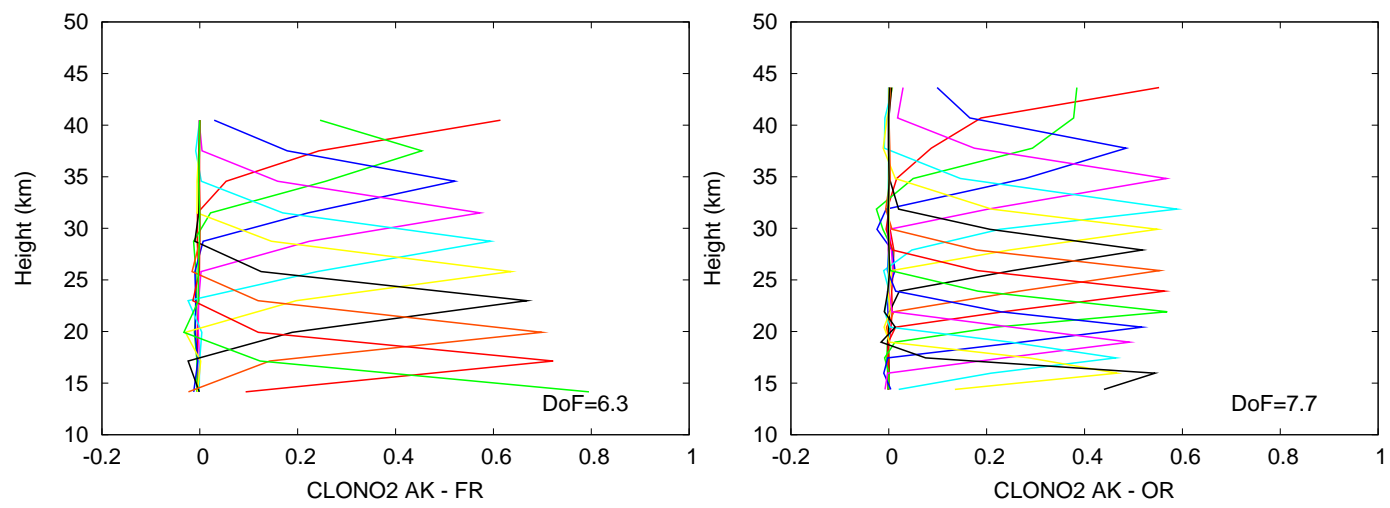

Figure 20: Same as Fig.11, but for $\mathrm{ClONO}_{2}$. 